\title{
POINT CLOUD MAPPING METHODS FOR DOCUMENTING CULTURAL LANDSCAPE FEATURES AT THE WORMSLOE STATE HISTORIC SITE, SAVANNAH, GEORGIA, USA
}

\author{
T. R. Jordan ${ }^{\mathrm{a} *}$, C. L. Goetcheus ${ }^{\mathrm{b}}$, M. Madden ${ }^{\mathrm{a}}$ \\ ${ }^{a}$ Center for Geospatial Research, Dept. of Geography, University of Georgia, Athens, GA USA - (tombob, mmadden)@uga.edu \\ ${ }^{\mathrm{b}}$ College of Environment and Design, University of Georgia, Athens, GA USA - cgoetch@uga.edu
}

Commission V, WG V/2

KEY WORDS: Cultural Landscape, Point Clouds, SfM, UAS

\begin{abstract}
:
Documentation of the three-dimensional (3D) cultural landscape has traditionally been conducted during site visits using conventional photographs, standard ground surveys and manual measurements. In recent years, there have been rapid developments in technologies that produce highly accurate 3D point clouds, including aerial LiDAR, terrestrial laser scanning, and photogrammetric data reduction from unmanned aerial systems (UAS) images and hand held photographs using Structure from Motion (SfM) methods. These 3D point clouds can be precisely scaled and used to conduct measurements of features even after the site visit has ended. As a consequence, it is becoming increasingly possible to collect non-destructive data for a wide variety of cultural site features, including landscapes, buildings, vegetation, artefacts and gardens. As part of a project for the U.S. National Park Service, a variety of data sets have been collected for the Wormsloe State Historic Site, near Savannah, Georgia, USA. In an effort to demonstrate the utility and versatility of these methods at a range of scales, comparisons of the features mapped with different techniques will be discussed with regards to accuracy, data set completeness, cost and ease-of-use.
\end{abstract}

\section{INTRODUCTION}

\subsection{Documenting the Cultural Landscape}

A cultural landscape is described as being an ecosystem, including its geographic location, geology, hydrology, soils and wildlife, overlain by a cultural system, which includes physical and cultural infrastructure, demographics and identity or sense of place. According to the U.S. National Park Service (NPS), a cultural landscape is a geographic area (including both cultural and natural resources and the wildlife or domestic animal therein), associated with a historic event, activity or person, or exhibiting other cultural or aesthetic values (Page et al., 1998).

This article addresses two national needs in cultural preservation technology: the need for more cost-effective data capture and manipulation tools, and the need for an assessment of digital documentation tools that are appropriate for cultural landscapes and their features.

Despite the high cost of laser scanning, it has become common place in the world of heritage documentation. Several articles indicate that less costly means of 3D data capture are needed (Harmon, et al., 2006; Gallagher and Josephie, 2008; Warden, 2009). There is a need for an assessment of cultural landscapespecific data capture and manipulation technology. Although some articles begin to address cultural landscape issues such as working with large tracts or forested areas (Risbol, et al., 2010), none were found that specifically address landscape characteristics, nor the accuracy and detail of the data capture for such features.

It is the goal of this paper to assess and compare several methods for documenting cultural landscape features using point cloud methods, including terrestrial laser scanning, and photogrammetrically derived point clouds from images acquired by small UASs and hand held cameras. These point clouds then may be used to provide permanent $3 \mathrm{D}$ documentation of the cultural features and will also permit additional information on the context of the natural landscape to be recorded and measurements made even after the field work is complete (Madden et al., 2015).

\subsection{Study Area}

The primary location of this research is the Wormsloe State Historic Site, which is located on the Isle of Hope just south of Savannah, Georgia, USA (Figure 1). Settled in 1734, Wormsloe is the oldest plantation in Georgia and the site of the oldest structure in Georgia: the fortified home built by the first owner, Nobel Jones. It is also significant in the fact that the property has been continuously maintained as a private home by

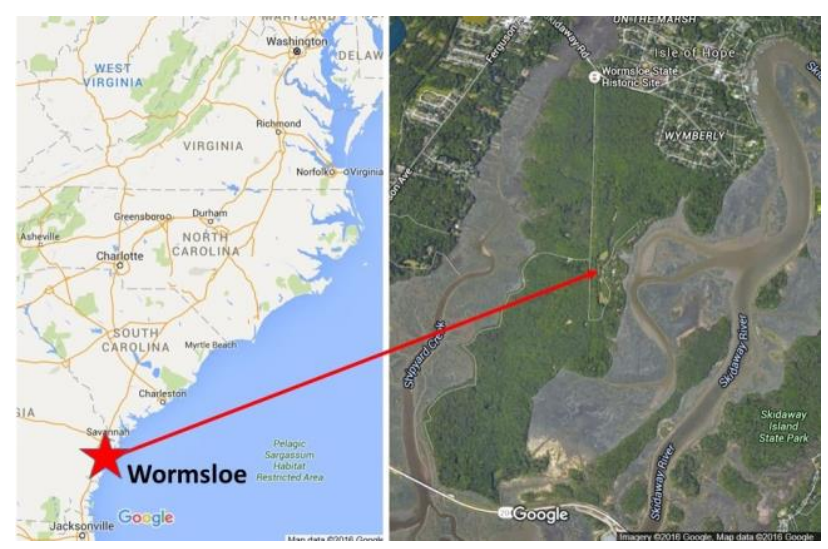

Figure 1. The Wormsloe State Historic Site is located on an interior barrier island just south of Savannah, Georgia, USA. 
descendants of Nobel Jones for nine generations. The 400-ha site is located on an interior barrier island surrounded by salt water marshes and creeks. Terrain relief is only a few meters and vegetation is predominately maritime forest with live oaks, loblolly pine and saw palmetto.

\subsection{Data Collection, Ground Control and Software}

A variety of equipment representing the range of costs and accuracies currently available was used to acquire point cloud and ground control data for this project. We cooperated with colleagues Georgia Southern University to provide terrestrial laser scans of various sites using a REIGL VZ-1000 System. Two small UASs were employed by us in the field: DJI Phantom 2 Vision+ and Phantom 4 quadcopters, each costing approximately 1,500 USD. The Phantom quadcopters are equipped with DJI cameras mounted on 3-axis stabilized gimbals. There were significant improvements in the camera between the Phantom 2 Vision+ and the Phantom 4, most noticeably in the reduction of lens distortion in the Phantom 4. Finally, a Sony DSC-HX200V digital SLR camera was used to acquire GPS-tagged hand held photos of cultural features in the field.

Three software packages were employed for data processing and visualization. Agisoft PhotoScan was used to create point clouds from sets of stereo images collected using the drones and hand held camera using Structure from Motion (SfM) methods. Applied Imagery's Quick Terrain Modeler permitted the georectification of point cloud data through the use of control points and direct measurement of point locations and distances in the point clouds. LAStools by rapidlasso $\mathrm{GmbH}$ was used primarily to scale datasets to match measurements of features in the field.

\section{CULTURAL FEATURE DOCUMENTATION}

\subsection{Principles and Goals}

We were interested in documenting several different types of cultural features using as many different methods as possible in order to best be able to compare ease-of-use, accuracy, completeness and cost. Two examples are presented here: a point cloud derived from Phantom 4 UAS images of the historic dock at Wormsloe; and second, the integration of aerial and terrestrial LiDAR data sets along with a model from hand held photos for the historic slave cabin at Wormsloe.

\subsection{The Historic Dock at Wormsloe}

The concrete dock at Wormsloe was built in about 1908 at the same time as other buildings such as the DeRenne Library were constructed (Figure 2). The dock has become one of the signature features defining Wormsloe and has been used as a location for movies in recent years. Today tourists from nearby Savannah visit the dock, library and nearby formal gardens as part of the "Old Savannah" itinerary. Built entirely of poured concrete, the dock extends $60 \mathrm{~m}$ from the shore to the outside wall of the pavilion.

Using the Point of Interest (POI) flight mode (new with the Phantom 4) which permits the aircraft to smoothly circle a point of interest at a particular distance, height and speed, high definition video of the dock pavilion was collected at two altitudes: 14 and $24 \mathrm{~m}$ above the ground level. A total of 192 overlapping individual frames were manually extracted from the video using VLC Media Player software and saved with a sequential numbering scheme. These video frames were not geotagged in any way prior to processing.

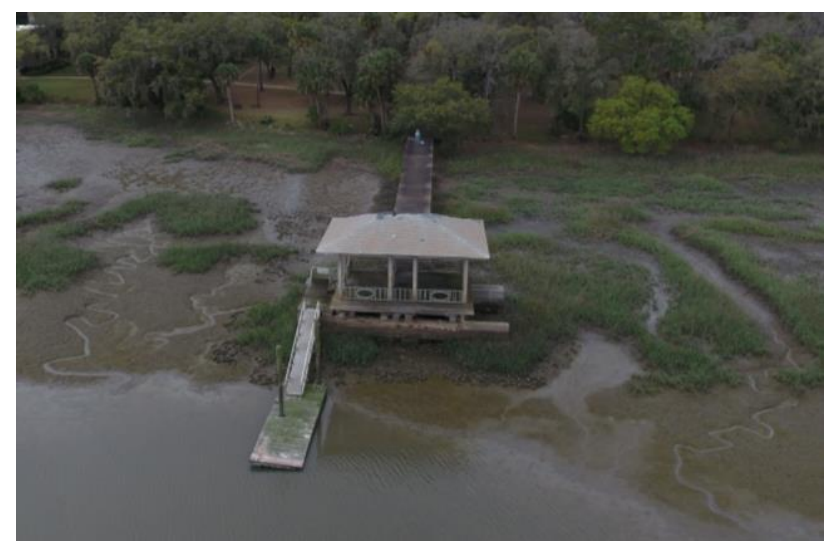

Figure 2. The historic concrete dock at Wormsloe.

The photographs were input to the Agisoft PhotoScan software and aligned automatically using the high accuracy setting. In this process, Structure from Motion (SfM) methods are employed to identify matching points in the photos and then reconstruct the geometry of the camera stations for each photo (or selected video frame) at the time of exposure (Figure 3). Any lens distortion in the camera is modelled out as part of the solution.

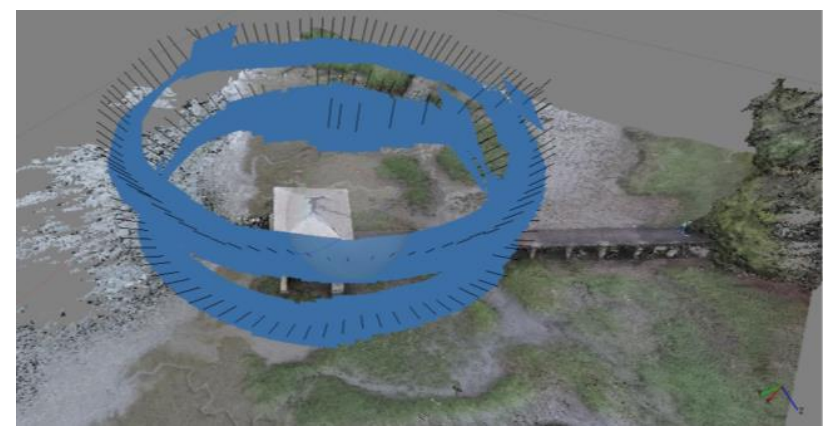

Figure 3. Camera positions of frames extracted from HD Video collected by Phantom 4 Quadcopter.

The next step is to create the dense point cloud from the video frames. Using the high density mode, a point cloud containing over 3 million points coded with RGB values was extracted from the photographs. The points were exported from PhotoScan as a standard LAS formatted file (Figure 4). Because the photos were not georeferenced during flight and had no IMU information attached, the point cloud was cast into a local coordinate space that was not calibrated to a particular system of units, such as feet or meters. Structural dimensions measured with a tape measure were used to scale the point cloud and length/width comparisons indicated the point cloud is accurate to approximately $4 \mathrm{~cm}$. Since the mostly automated UAS flight was 20-minutes in duration, data volume was about $2 \mathrm{~Gb}$ from which frames totalling about $500 \mathrm{Mb}$ were extracted. As data processing was completed in about 2 hours on a standard laptop computer, this method was deemed to be relatively easy, low cost and accessible to most individuals. This point cloud was viewed in 3D using the Quick Terrain Modeler software. 


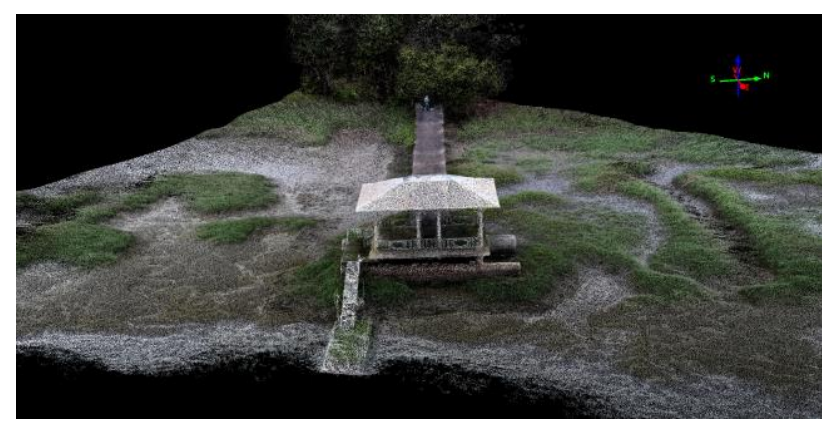

Figure 4. Point cloud of the dock at Wormsloe.

\subsection{The Slave Cabin at Wormsloe}

At the same time as the data capture for the Wormsloe dock, a series of 214 hand held ground photographs were recorded using the Sony DSC-HX200V DSLR camera from positions around an historic slave cabin dating back to approximately 1840 (Figure 5). These images were recorded at $18.2 \mathrm{Mp}$ resolution. Each of the photos was geotagged with the latitude/longitude coordinates of its location using the integrated GPS in the camera. The accuracy of these coordinates is unknown but assumed to be on the order of a consumer grade GPS unit or about 3-4 m. In addition, a tape measure was used to measure the dimensions of the building.

The photographs were loaded into Agisoft PhotoScan and aligned using the SfM method. Following alignment, a dense point cloud was created using the high density option. Upon completion of this processing step, the resulting point cloud containing 5,165,000 points was loaded into QT Modeler for examination and review (Figure 6)

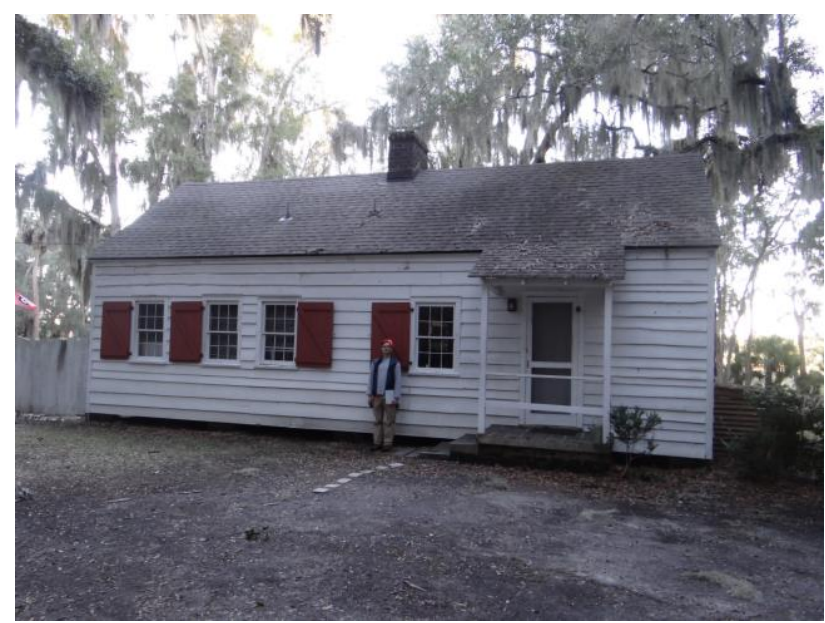

Figure 5. The original slave cabin at Wormsloe is now used for research housing.

Measurements of the length and width of the cabin were made in the field with a tape measure and then the same measurements made in the point cloud (Table 1). Using a constant scale factor of 1.0407, the point cloud was rescaled in XYZ using LASTools. After the resulting scaled point cloud was remeasured in QT Modeler, it was found that the difference between the measured dimensions and the point cloud dimensions was $1 \mathrm{~cm}$ in length and $6 \mathrm{~cm}$ in width.

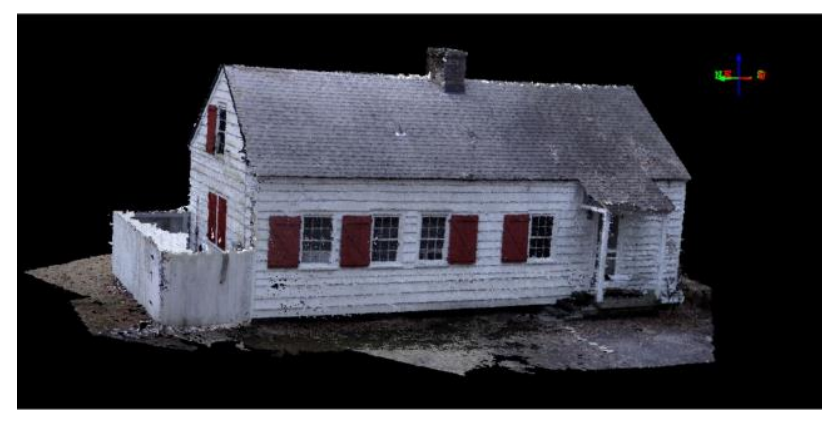

Figure 6. Point cloud from hand held photos of slave cabin.

\begin{tabular}{|l|l|l|l|}
\hline Dimension & Measurement & Before scaling & After scaling \\
\hline Length & $11.7 \mathrm{~m}$ & 11.21 & 11.69 \\
\hline Width & $5.6 \mathrm{~m}$ & 5.37 & 5.66 \\
\hline
\end{tabular}

Table 1: Measurements made on the slave cabin point cloud.

In addition to hand held ground photographs as input to SfM software, a REIGL VZ-1000 System provided by Georgia Southern University was used to acquire terrestrial laser scan data of the historic slave cabin. A total of three setups were required for data collection of the cabin and the immediate landscape to capture the terrain and surrounding live oak trees draped in Spanish moss. It took approximately one hour to collect the data that totalled over $1.5 \mathrm{~Gb}$. This method also required a skilled and knowledgeable operator with two field assistants who placed cylindrical targets in the area of the scans to be used as 3D GCPs. The resulting point cloud was extremely dense with point spacing of only a few millimeters and coordinate accuracy estimated to be on the order of $1-2 \mathrm{~cm}$. Details in the roof structure, small items on the porch and delicate Spanish moss draping the live oak limbs was impressive (Figure 7)

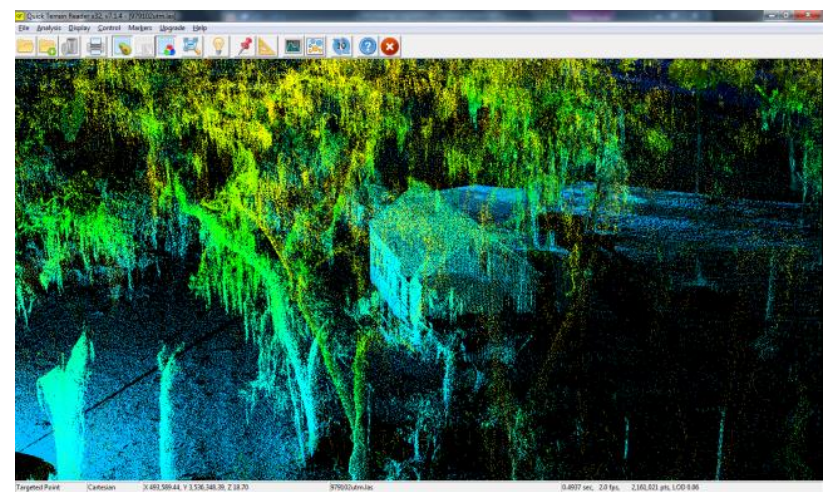

Figure 7. Terrestrial laser scan of the slave cabin. Note the Spanish moss hanging from the limbs of the live oak trees.

Finally, airborne LiDAR was obtained for the Wormsloe cabin site as part of a county-wide data collection in 2006. A point cloud of approximately one point per square meter was provided to us by the Chatham County Geographic Information System (GIS) Department. Covering the entire Isle of Hope and providing an environmental context for the cultural heritage site, the aerial LiDAR was integrated with the terrestrial laser scan data to create a seamless $3 \mathrm{D}$ point cloud. The advantage of the combined dataset is the cabin is obscured in the aerial LiDAR data due to dense tree canopy. Adding the terrestrial 
laser scan point cloud provides 3D data of the cabin within its landscape setting (Figure 8).

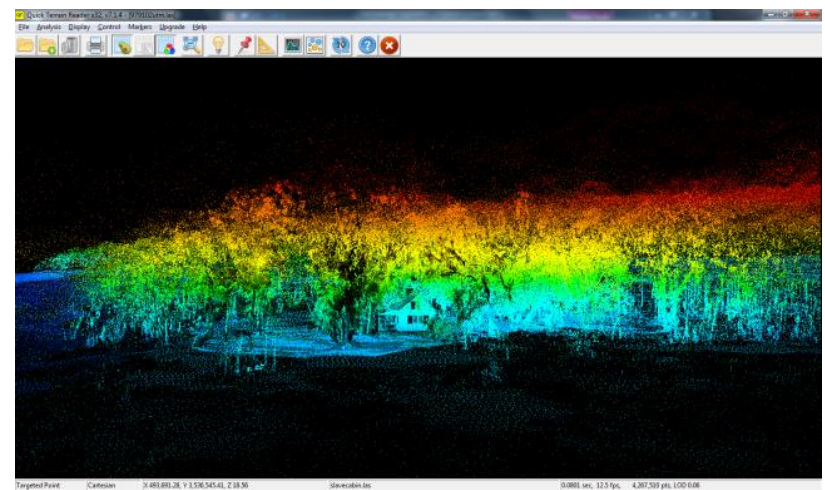

Figure 8. Integrated aerial LiDAR and terrestrial laser scan data for the slave cabin area at Wormsloe.

\section{CONCLUSIONS}

Cultural landscapes contain a wide range of features, including gardens, buildings, walls and vegetation. Each type of feature and, in fact, each individual feature, requires careful consideration on how to document it properly to permit the archiving of the current condition and status. A 3D point cloud depicting the cultural features within their surrounding landscape captures baseline information that can be reexamined at some point in the future. Unfortunately, cultural features and landscapes are often neglected or even destroyed to make way for new development. Point clouds and associated optical imagery preserves information on cultural feature materials, construction and condition. Integrated point clouds obtained from a variety of platforms using different methods can be used to visualize and measure features from broad to fine scales and ensures completeness in cases of scanning occlusion.

The results of these examinations demonstrate that although it is possible to achieve excellent results using high quality survey and scanning equipment, it is also possible to get very good accuracy using equipment of lower cost and complexity. In fact, as far as accuracy and completeness goes, the point clouds created from the Phantom UASs were adequate for cultural feature documentation, archival and visualization. In addition, the point clouds created from hand held photos were comparable in point density and almost as good geometrically as the terrestrial laser scans. In this case, the lower tech solution provides cost savings that are significant on both equipment and training while providing data that is suitable in quality for cultural landscape documentation.

\section{ACKNOWLEDGEMENTS}

Funding for this project was provided by the Wormsloe Institute for Environmental History, the University of Georgia Geography-Center for Geospatial Research and College of Environment and Design. Special thanks are extended to Dr. C.J. Jackson and his students from Georgia Southern University for terrestrial laser scanning data collection and to Craig and Diana Barrow and Sarah Ross for their support and access to this fantastic study site.

\section{REFERENCES}

Gallagher, J.M. and R.L. Josephie, 2008. Using LiDAR to detect cultural resources in a forested environment: an example from Isle Royale National Park, Michigan, USA. Archeological Prospection 15. pp. 187-206.

Harmon, J.M., M.P. Leone, S.D. Prince and M. Snyder, 2006. Lidar for Archaeological Landscape Analysis: A Case Study of Two Eighteenth-Century Maryland Plantation Sites. American Antiquity, 71(4). pp. 649-670.

Madden, M., T. Jordan, S. Bernardes, D. Cotten, N. O'Hare and A. Pasqua, 2015. Unmanned Aerial Systems (UAS) and Structure from Motion (SfM) Revolutionize Wetlands Mapping, Invited Chapter In, R. Tiner, M. Lang and V. Klemas (Eds), Remote Sensing of Wetlands: Applications and Advances, CRC Press Taylor \& Francis Group, Boca Raton, Florida, 10: 195222.

Madden, M., T. Jordan, S. Bernardes, D. Cotten, N. O'Hare and A. Pasqua, 2015b. The Future of Unmanned Aerial Systems (UAS) for Natural and Cultural Resource Monitoring, Proceedings of Photogrammetric Week, Institute of Photogrammetry, University of Stuttgart, Germany, pp. 369385 .

Page, R., C. Gilbert, and S. Dolan, 1998. A Guide to Cultural Landscape Reports: Contents, Process and Techniques. Washington, D.C.: US Department of the Interior.

Risbol, O., A.K. Gjertsen, K. Sjare, 2010. Airborne laser scanning of cultural remains in forests - some preliminary results form a Norwegian project. Remote Sensing for Archeological Heritage Management, Proceedings of the 11th EAC Heritage Management Symposium.

Warden, R., 2009. Towards a New Era of Cultural-Heritage Recording and Documentation. APT Bulletin, 40(3/4). pp. 5-10. 